\title{
VITIMIZAÇÃO DE ESTUDANTES UNIVERSITÁRIOS EM SUA MOBILIDADE URBANA EM RIO CLARO, SÃO PAULO
}

\author{
Farid Nourani ${ }^{1}$ \\ Sérgio Luis Antonello ${ }^{2}$ \\ José Silvio Govone ${ }^{3}$
}

\begin{abstract}
Resumo: Este artigo apresenta alguns resultados de uma pesquisa realizada com estudantes da UNESP, Campus de Rio Claro, para avaliar alguns fatores relacionados à sua vitimização na mobilidade urbana, com foco na vitimização sexual das mulheres em meios de transporte público. Neste estudo foram analisadas as inter-relações entre características pessoais, influências socioculturais e condições de infraestrutura de ambientes relacionados a transporte urbano. A pesquisa foi realizada no primeiro semestre de 2018, quando foram coletados 462 questionários com respostas válidas. O perfil dos participantes se constituiu de $46,6 \%$ do sexo feminino e $42,6 \%$ do sexo masculino, sendo $69,7 \%$ de brancos e $19,5 \%$ de não-brancos (por auto declaração). Estudantes que declararam pertencer ao grupo LGBT+ representam $19,8 \%$ do total de respondentes. Os estudantes da UNESP usam 6 diferentes modais de transporte: bicicleta, carro, motocicleta, táxi, transporte por aplicativo e ônibus. Os grupos de estudantes mais vulneráveis foram identificados como LGBT+ com $31,7 \%$ de vítimas, mulheres com $26,5 \%$ de vítimas e não-brancos com $21,4 \%$ de vítimas.
\end{abstract}

Palavras-chave: Transporte Público; Assédio Sexual; Vitimização de Mulheres; Violência Urbana; Mobilidade Urbana.

\section{VICTIMIZATION OF UNIVERSITY STUDENTS IN THEIR URBAN MOBILITY IN RIO CLARO, SÃO PAULO}

Abstract: This article presents some results of a research carried out among UNESP
students at Rio Claro Campus, to evaluate some factors related to their victimization
in their urban mobility with a focus on the sexual victimization of women in public
transportation. In this study was analyzed the intersectionality between personal
characteristics, socio-cultural influences and infrastructure conditions of urban
transportation environments. The survey was conducted in the first semester of 2018

${ }^{1}$ Universidade Estadual Paulista (UNESP). farid.nourani@unesp.br
${ }^{2}$ Professor da Fundação Hermínio Ometto (FHO). Analista de Informática do Centro de Análise e Planejamento Ambiental
(CEAPLA) do Instituto de Geociências e Ciências Exatas (IGCE) da Universidade Estadual Paulista (UNESP), Campus Rio
Claro. Doutor em Ecologia Aplicada pela Universidade de São Pulo (USP). sergio.antonello@ unesp.br
${ }^{3}$ Professor do Departamento de Estatística, Matemática Aplicada e Computação (DEMAC) do Instituto de Geociências e
Ciências Exatas (IGCE) da Universidade Estadual Paulista (UNESP), Campus Rio Claro. Doutor em Ciências da Engenharia
Ambiental pela Universidade de São Paulo (USP). js.govone@ unesp.br
Estudos Geográficos, Rio Claro, 17(1): 175-195, jan./jun. 2019 (ISSN 1678-698X)

http://www.periodicos.rc.biblioteca.unesp.br/index.php/estgeo 
when 462 questionnaires with valid answers were collected. The profile of the participants represents $46.6 \%$ female and $42.6 \%$ male, with $69.7 \%$ whites and $19.5 \%$ non-whites (by self-declaration). Students who reported belonging to the LGBT+ represent $19.8 \%$ of the total respondents. UNESP students use 6 different modes of transportation: bicycle, car, motorcycle, taxi, ride-hailing services and bus. The most vulnerable groups of students were identified as LGBT+ with $31.7 \%$ of victims, women with $26.5 \%$ of victims and nonwhites with $21.4 \%$ of victims.

Keywords: Public Transportation; Sexual Harassment; Women Victimization; Urban Violence; Urban Mobility.

\section{INTRODUÇÃO}

Este trabalho apresenta alguns resultados de uma pesquisa de opinião, realizada junto aos alunos da Universidade Estadual Paulista (UNESP), Campus de Rio Claro. Esta pesquisa, apoiada pelo Centro de Análise e Planejamento Ambiental (CEAPLA) e coordenada pelos autores deste trabalho, faz parte de um estudo internacional, realizado simultaneamente em 17 cidades ao redor do mundo, coordenado internacionalmente pelas Professoras Vania Ceccato do Instituto Real de Tecnologia da Suécia (KTH) e Anastasia Loukaitou-Sideris da Universidade de Califórnia em Los Angeles (UCLA).

O objetivo principal do estudo é avaliar e comparar a vitimização de estudantes universitários no transporte público, com foco na vitimização sexual das mulheres. As cidades que compõem o escopo deste estudo são: Estocolmo, na Suécia; Los Angeles, nos Estados Unidos da América; Londres, na Inglaterra; Milão, na Itália; Novo México, no México; Bogotá, na Colômbia, Rio Claro e São Paulo, no Brasil; Paris, na França; Melbourne, na Austrália; Tóquio, no Japão; San Salvador, na Guatemala; Vancouver, no Canadá; Lagos, na Nigéria; Guangzhou, na China; Pretória, na África do Sul e Manila, nas Filipinas. Alguns resultados apresentados neste trabalho visam uma futura análise comparativa com os resultados de outras cidades do estudo, tão logo sejam disponibilizados os dados dos resultados da pesquisa nas demais cidades.

Como os colaboradores da Rede de Locais Seguros (Safeplaces Network) têm demonstrado (CECCATO, 2017; SAKRAPLASTSER, 2018), a vitimização das pessoas, em especial as mulheres, e o seu direito intrínseco à mobilidade e ao acesso seguro a lugares públicos, têm atraído a atenção e a atuação de um número significativo de pesquisadores ao redor do mundo. De certa forma, o acesso seguro a lugares públicos tem se tornado uma necessidade veemente da sociedade moderna para estabelecer o mínimo de condições igualitárias e dignas para várias parcelas significativas da humanidade, principalmente as mulheres.

Em todo o mundo, as mulheres e a comunidade LGBT+ são frequentemente alvo de agressão e violência sexual enquanto estão em trânsito (CECCATO; PAZ, 2017; GEKOSKI et al., 2015; LOUKAITOU-SIDERIS, 2014; VANIER; D'ARBOIS, 2017). Neste contexto, é importante o conhecimento mais apurado sobre vários aspectos desta temática, tais como: reação das pessoas quanto ao medo da violência no transporte público; situações mais temidas pelas pessoas; os grupos mais vulneráveis enquanto estão em trânsito; mudanças comportamentais para enfrentar as situações temíveis e medidas mitigadoras destas situações.

Estudos Geográficos, Rio Claro, 17(1): 175-195, jan./jun. 2019 (ISSN 1678-698X) http://www.periodicos.rc.biblioteca.unesp.br/index.php/estgeo 
A compreensão destas questões não é uma tarefa fácil, embora seja extremamente importante e necessária, pois contribui para a análise dos fatores que afetam a sensação de segurança das pessoas, bem como na busca de estratégias e medidas que possam proporcionar maior sensação de segurança e, consequentemente, maior bem-estar.

A pesquisa realizada em Rio Claro pode ser considerada como um ensaio inicial na busca de informações que facilitem a compreensão de alguns dos aspectos acima mencionados, além de cumprir o seu papel no estudo internacional. Além disso, como descrito nas próximas seções deste trabalho, alguns resultados se mostraram bastante significativos e podem servir como estímulo a investigações mais profundas e certamente mais profícuas.

Este trabalho está organizado da seguinte forma: na próxima seção são apresentadas algumas informações sobre a cidade de Rio Claro e seus índices de violência, além de taxas de violência contra mulheres no Brasil. Apesar destes índices não estarem diretamente relacionados ao público objeto de estudo deste trabalho, eles foram incluídos neste trabalho a fim de oferecer ao leitor uma visão sobre o nível de violência em Rio Claro e no Brasil. Pois, acredita-se que o elevado nível de sensação de insegurança no transporte público, relatado pelos participantes desta pesquisa, pode estar relacionado, em grande medida, ao desamparo que a população brasileira sente em relação à questão da segurança pública, refletido nos diversos índices oficiais.

$\mathrm{Na}$ seção seguinte é apresentada a metodologia empregada nesta pesquisa e o perfil da amostra dos estudantes pesquisados. Em seguida são apresentados os resultados da coleta de dados e análises em três abordagens complementares: através do prisma de características pessoais dos participantes, através do prisma de influências do meio cultural e urbano e através do prisma de qualidade da infraestrutura de transporte e de políticas públicas. Por fim, são apresentadas as considerações finais e perspectivas futuras de trabalho nesta área.

\section{A CIDADE DE RIO CLARO}

Rio Claro é uma cidade de médio porte, com população aproximada de 204.000 habitantes, tem uma área de $498 \mathrm{~km}^{2}$ e densidade demográfica de cerca de 373 hab. $/ \mathrm{km}^{2}$ (IBGE, 2018). Localizada no estado de São Paulo, a cidade fica 173 km distante da capital do estado (São Paulo) por via rodoviária. Inserida na Região Administrativa de Campinas (o segundo maior polo industrial do Estado), faz parte de uma microrregião bastante desenvolvida e em constante expansão econômica. Rio Claro fica a $240 \mathrm{~km}$ do porto de Santos, a $85 \mathrm{~km}$ do Aeroporto Internacional de Viracopos (o segundo principal terminal de cargas do Brasil) e a $200 \mathrm{~km}$ do Aeroporto Internacional de Guarulhos, na região metropolitana da capital.

Rio Claro possui uma rede de transporte composta por ferrovias (operando somente para cargas), rodovias, rodovias intermunicipais, terminal rodoviário e um aeroporto com $1.500 \mathrm{~m}$ de pista, adequado para pouso de pequenas aeronaves. Tem o privilégio de estar inserida na região que se distingue pela maior extensão de suas estradas, pela qualidade do revestimento das pistas e pelo volume de tráfego médio diário, sendo uma das cidades atendidas por três das melhores rodovias do país (Bandeirantes, Anhanguera e Washington Luiz).

A região é caracterizada pela presença maciça de centros industriais, diversificados ou especializados, onde indústrias modernas estão presentes. Um

Estudos Geográficos, Rio Claro, 17(1): 175-195, jan./jun. 2019 (ISSN 1678-698X) http://www.periodicos.rc.biblioteca.unesp.br/index.php/estgeo 
grande destaque da microrregião de Rio Claro é que o município, em conjunto com outras três cidades (Santa Gertrudes, Cordeirópolis e Ipeúna), compõe o maior polo cerâmico das Américas, abastecendo os mercados nacional e internacional (CABRAL JUNIOR; GAMBA, 2017; MELLO, 2015; CARNEIRO et al., 2009).

No entanto, estatísticas oficiais da Secretaria Estadual de Segurança Pública (SSP-SP) apresentam altas taxas de criminalidade para uma cidade do perfil de Rio Claro, considerando os padrões nacionais e internacionais. Uma simples análise quantitativa do número de crimes registrados indica que o município de Rio Claro sempre apresentou taxas de homicídio superiores às cidades vizinhas, muitas delas, com características semelhantes às de Rio Claro (CARNEIRO et al., 2009).

A taxa de homicídios de Rio Claro, em média, sempre se manteve em patamares superiores às taxas dos demais municípios da região. No período de 2013 a 2017 essa taxa foi de 15,51 por 100 mil habitantes, sendo quase o dobro da taxa média do estado no mesmo período (8,99 por 100 mil habitantes) ou da cidade de São Paulo, a capital do estado (8,40 por 100 mil habitantes). Outra estatística que chama atenção é o índice de furtos na cidade, tanto para objetos como para veículos, que também são superiores às médias do estado e às médias das cidades da região. As médias de Rio Claro para estes delitos são, respectivamente, 1281,21 por 100 mil habitantes e 495,53 por 100 mil veículos, contra médias estaduais de 1202,48 por 100 mil habitantes e 432,94 por 100 mil veículos, respectivamente (SÃO PAULO, 2018).

No Brasil, estudos mostram que os índices de violência contra mulheres, jovens e minorias étnicas, especialmente as taxas de mortes violentas, têm aumentado nos últimos anos (CARVALHO; OLIVEIRA, 2017; RAMOS, 2017; SILVA et al., 2017; CERQUEIRA, 2018). Em geral, a taxa média nacional de mortes violentas nos últimos 5 anos é de 24 ocorrências por 100.000 habitantes (AMÂNCIO, 2017). Em se tratando de violência sexual, dados do Instituto de Pesquisa Econômica Aplicada (IPEA) mostram que as taxas médias de estupro por 100.000 habitantes no período de 2012 a 2016 são de 30,32 para mulheres adultas e 51,4 para meninas menores de 13 anos (CERQUEIRA, 2017). Apesar desses estudos, pouco se sabe sobre a sensação de insegurança e medo entre os jovens, em particular entre as mulheres e o grupo LGBT+.

Independentemente das diferentes formas de violência, em geral no Brasil a mulher tem sido vítima com maior frequência. Isto se deve a diferentes causas culturais, principalmente o histórico machismo presente na sociedade brasileira. Em Rio Claro a situação não é diferente. Diversas iniciativas de órgãos e autoridades municipais demonstram esta preocupação, que resultou em várias ações, objetivando a redução dos índices de violência contra mulheres.

A Guarda Civil Municipal de Rio Claro, por exemplo, criou a 'Patrulha Maria da Penha', com o objetivo de proteger, prevenir, monitorar e acompanhar as mulheres vítimas de violência doméstica ou familiar, no município (RIO CLARO, 2018). A Secretaria Municipal de Cultura de Rio Claro também promoveu em março de 2019, pela segunda vez, uma exposição sobre o tema, por meio de relatos de mulheres vítimas de violência física, sexual e psicológica, com o título "A Culpa é Minha?", seguindo o exemplo da Bélgica (BBC-NEWS, 2018). Trajes similares aos usados por algumas mulheres nos momentos das agressões foram expostos, com 0 objetivo de desconstruir a ideia equivocada de culpar a mulher pela violência sofrida (GRUPORIOCLAROSP, 2019).

O município de Rio Claro também apresenta altos níveis de acidentes de trânsito, frequentemente com lesões físicas e vítimas fatais. As estatísticas oficiais

Estudos Geográficos, Rio Claro, 17(1): 175-195, jan./jun. 2019 (ISSN 1678-698X) http://www.periodicos.rc.biblioteca.unesp.br/index.php/estgeo 
apontam Rio Claro entre as 100 cidades nacionais com maior letalidade no trânsito (CARNEIRO et al., 2009). A frota de veículos do município cresceu muito nos últimos anos, principalmente em relação ao número de automóveis e motocicletas ou motonetas, representando alta porcentagem de veículos da cidade. Quanto aos demais veículos automotores (caminhões, ônibus e micro-ônibus), o crescimento foi mais modesto.

Como demonstrado nos trabalhos de Souza et al. (2009) e Grotta (2001) a pouca efetividade do transporte público, aliado a características geomorfológicas da cidade, privilegia e estimula o transporte individual em Rio Claro. Os resultados do presente estudo indicam também esta tendência entre os estudantes da UNESP. Assim, nota-se que o município, tradicionalmente, deixa de adotar políticas públicas que estimulem o transporte coletivo e que diminuam o uso de veículos particulares em determinados horários e locais, diminuindo os altos índices de acidentes de trânsito (Carneiro, 2013). Desenvolver políticas públicas que melhorem a sensação de segurança no transporte coletivo contribui no sentido de tornar este tipo de transporte mais atrativo à população.

\section{METODOLOGIA}

Neste trabalho foi realizada uma pesquisa quantitativa por meio de aplicação de um questionário com abordagem de autoadministração, empregando tanto a técnica online como a técnica papel e lápis. O questionário foi elaborado pelos coordenadores do projeto a nível internacional e traduzido do inglês para o português pela equipe do CEAPLA, em parceria com outra equipe brasileira participante do projeto, a equipe da Universidade de São Paulo (USP). Um mesmo questionário padrão foi utilizado em todas as cidades participantes do estudo internacional, porém, com pequenas modificações. Por exemplo, no caso de Rio Claro, não foram incluídas questões sobre as condições de metrô e nem sobre o uso de trólebus, uma vez que não existem estas modalidades de transporte em Rio Claro. Entretanto, foram incluídas questões sobre uso de bicicleta e motocicleta. Contudo, para manter a padronização do questionário em todas as cidades participantes, não eram permitidas adaptações nos textos e nas estruturas das questões. Posteriormente o questionário foi aplicado de forma voluntária e anônima, junto aos estudantes do Campus de Rio Claro da UNESP.

O questionário é composto de 38 questões de múltipla escolha, agrupadas em quatro seções: uso de ônibus, denúncia de crime, transporte privado, perfil do respondente. A seção sobre o uso de ônibus é composta de 12 questões, que abrangem a frequência e os horários de uso, a sensação de segurança, principais impedimentos de uso e principais problemas do sistema de transporte público, situações de assédio e agressões sofridas, eventuais precauções usadas e sugestões para melhoria do sistema de transporte coletivo.

A seção de denúncia de crime é composta de 10 questões, que tentam investigar os diversos tipos de crimes sofridos pelos respondentes, nos últimos 3 anos, a condição e a quantidade de casos denunciados, além dos motivos da não denúncia dos casos não denunciados. A seção de transporte privado, também com 10 questões, tenta levantar as estatísticas de uso de outros modais de transporte pelos estudantes. Finalmente, a seção sobre o perfil do respondente, que contem 6 questões, fornece informações sobre características individuais dos respondentes, tais como gênero, idade, etnia, orientação sexual, etc.

Estudos Geográficos, Rio Claro, 17(1): 175-195, jan./jun. 2019 (ISSN 1678-698X) http://www.periodicos.rc.biblioteca.unesp.br/index.php/estgeo 
Distribuída em 24 cidades do estado de São Paulo, a UNESP é uma universidade multicampi, composta por 34 unidades universitárias e várias outras unidades complementares e auxiliares. No Campus de Rio Claro existem dois Institutos, o Instituto de Geociências e Ciências Exatas (IGCE) e o Instituto de Biociências (IB), uma Unidade Complementar, o Centro de Estudos Ambientais (CEA) e duas Unidades Auxiliares, o Centro de Análise e Planejamento Ambiental (CEAPLA) e o Centro de Estudos de Insetos Sociais (CEIS).

Segundo os dados fornecidos em fevereiro de 2019 pelas Diretorias dos dois Institutos, com base nas matrículas realizadas em 2018, o IGCE oferece oito cursos de graduação com 1.293 alunos (461 mulheres e 832 homens) e sete programas de pós-graduação com 364 alunos (160 mulheres e 204 homens). O IB oferece cinco cursos de graduação com 1.092 alunos (671 mulheres e 421 homens) e nove programas de pós-graduação com 504 alunos (292 mulheres e 212 homens). No total existem 3.253 alunos no Campus de Rio Claro da UNESP $(48,7 \%$ mulheres, $51,3 \%$ homens).

Inicialmente, o questionário foi disponibilizado pela internet, através da plataforma Google Forms, por um período de 32 dias (15/05 a 17/06/2018). Entretanto, apesar de uma massiva divulgação no Campus de Rio Claro, por meio de faixas, cartazes, redes sociais e envio de e-mails, a adesão dos estudantes à pesquisa foi muito baixa. Diante disso, decidiu-se mudar a estratégia e aplicar o questionário usando a técnica papel e lápis, oferecendo-o aos estudantes em diversos ambientes do Campus, como por exemplo, no Restaurante Universitário, na Biblioteca, na Cantina e em salas de aula com colaboração de outros docentes do IGCE.

Estabeleceu-se, então, um novo período de coleta de dados, de 20/06 a 31/07/2018, com uma nova campanha de divulgação. O questionário online também continuou disponível na plataforma Google pelo mesmo período. Assim, foram coletadas respostas de 569 estudantes, tanto de forma eletrônica quanto de forma tradicional e presencial. Desse total, 107 respostas foram descartadas por conterem algum tipo de inconsistência, resultando em 462 respostas válidas. Posteriormente, todas as respostas válidas obtidas no formato em papel foram digitalizadas utilizando o questionário online em Google Forms.

As análises foram realizadas utilizando a planilha de dados correspondente ao formulário Google e os recursos do software Microsoft Excel. O método da Tabulação Cruzada foi utilizado para compreender e explicar a correlação entre diferentes variáveis. Em algumas análises foram utilizados o teste do Qui-quadrado de Pearson, bem como os conceitos de Risco Relativo e Razão das Chances, para avaliar a comparação dos dados e consequentemente a compreensão dos resultados. Entretanto, os detalhes dessas análises não foram incluídos neste trabalho.

\section{INFLUÊNCIA DAS CARACTERÍSTICAS INDIVIDUAIS}

Inicialmente se faz necessário observar a distribuição dos estudantes que responderam ao questionário em termos do gênero, etnia e idade. Como é mostrado na Tabela 1, pode-se considerar que há um certo equilíbrio entre a quantidade de estudantes participantes femininos (46,6\%) e masculinos (42,6\%).

Considerando a etnia dos participantes da pesquisa, $70,1 \%$ se declararam brancos, enquanto $19,1 \%$ se autodeclararam entre as etnias não brancas. A grande

Estudos Geográficos, Rio Claro, 17(1): 175-195, jan./jun. 2019 (ISSN 1678-698X) http://www.periodicos.rc.biblioteca.unesp.br/index.php/estgeo 
maioria dos participantes é jovem de até 29 anos (94\%) e 5,4\% tem a idade entre 30 e 49 anos, enquanto os adultos maiores de 49 somam apenas 0,6\%. Já os estudantes que afirmaram pertencer ao grupo LGBT+ representam 17,8\% do total de participantes.

\section{Tabela 1 - Distribuição de participantes em grupos por variáveis de gênero, LGBT+, etnia e idade}

\begin{tabular}{|c|c|c|c|c|c|}
\hline \multirow{2}{*}{$\begin{array}{l}\text { Grupos } \\
\text { Gênero }\end{array}$} & Indivíduos & $\%$ & \multirow{2}{*}{$\begin{array}{l}\text { Grupos } \\
\text { Etnia }\end{array}$} & \multirow[t]{2}{*}{ Indivíduos } & \multirow[t]{2}{*}{$\%$} \\
\hline & & & & & \\
\hline Feminino & 215 & 46,6 & Branco & 324 & 70,1 \\
\hline Masculino & 197 & 42,6 & Não Branco & 88 & 19,1 \\
\hline $\mathrm{PNC}^{*}$ & 6 & 1,3 & $\mathrm{PNC}^{*}$ & 8 & 1,7 \\
\hline Não Declarou & 44 & 9,5 & Não Declarou & 42 & 9,1 \\
\hline Total & 462 & 100 & Total & 462 & 100 \\
\hline LGBT+ & & & Idade & & \\
\hline Sim & 82 & 17,8 & Menores de 30 & 434 & 94,0 \\
\hline Não & 324 & 70,1 & Entre 30 a 49 & 25 & 5,4 \\
\hline $\mathrm{PNC}^{*}$ & 8 & 1,7 & Maiores de 49 & 3 & 0,6 \\
\hline Não Declarou & 48 & 10,4 & Total & 462 & 100 \\
\hline Total & 462 & 100 & & & \\
\hline
\end{tabular}

PNC - Prefere Não se Classificar

Fonte: Pesquisa de Campo

No questionário em Rio Claro foram considerados 6 modais de transporte: ônibus, carro, táxi, transporte por aplicativo, bicicleta e motocicleta, já que o trem é usado exclusivamente para transporte de carga. Os resultados permitiram estabelecer o seguinte "ranking", com correspondentes porcentagens de uso pelos estudantes: Bicicleta com 48,3\%, Carro com 26,4\%, Transporte por aplicativo com 20,6\%, Ônibus com 8,0\%, Taxi com 6,0\% e Motocicleta com 5,8\% de usuários. Notar que cada participante poderia escolher mais de uma modalidade, motivo pelo qual a soma ultrapassa $100 \%$.

Além disso, analisando o gênero, é interessante observar que são as estudantes do sexo feminino que utilizam mais carro $(51,9 \%$ de mulheres contra $47,2 \%$ de homens), mais transporte por aplicativo (54,3\% de mulheres contra $42 \%$ de homens) e mais motocicleta $(65,2 \%$ de mulheres contra $34,8 \%$ de homens). Elas empatam com os homens no uso de taxi $(46,4 \%)$ e de bicicleta $(48,0 \%$ de mulheres e $50,0 \%$ de homens), mas usam menos ônibus (37,8 de mulheres contra $46,0 \%$ de homens).

No questionário aplicado havia três perguntas explicitas para obter a proporção de estudantes que foram vítimas dos seguintes tipos de crime dentro do ônibus, no ponto de ônibus ou no caminho a pé de/para o ponto de ônibus:

a. abuso ou assédio sexual;

b. outros crimes de potencial gravidade (assalto, estupro, etc.);

c. roubo/batedor de carteira.

A Tabela 2 apresenta os dados relacionados às respostas coletadas sobre estas três categorias de crime, onde para cada tipo existem 3 linhas de informação. A primeira linha representa a distribuição das porcentagens de vítimas conforme 0 Estudos Geográficos, Rio Claro, 17(1): 175-195, jan./jun. 2019 (ISSN 1678-698X) http://www.periodicos.rc.biblioteca.unesp.br/index.php/estgeo 
gênero, se pertencente ao grupo LGBT+ e etnia dos estudantes participantes. Na última coluna está a porcentagem de vítimas em relação ao total da amostra (462 indivíduos).

A segunda linha representa a distribuição dos percentuais de vítimas de cada grupo de pessoas em relação ao total de pessoas do mesmo grupo que responderam a questão correspondente àquele crime. Por exemplo, no caso do crime de abuso ou assédio sexual, $26,5 \%$ do total de estudantes do sexo feminino foram vitimadas, enquanto entre os participantes do sexo masculino esse percentual é de 8,2.

A terceira linha mostra a distribuição dos percentuais de vítimas de cada grupo de pessoas que denunciaram o crime sofrido, em relação ao total de vítimas do próprio grupo. Por exemplo, no caso do crime de abuso ou assédio sexual, apenas $22,8 \%$ das mulheres denunciaram o crime sofrido, enquanto somente $13,3 \%$ dos estudantes do sexo masculino reportaram ter denunciado o crime sofrido. Em relação ao total de vítimas, $20,0 \%$ denunciaram o delito sofrido.

\section{Tabela 2 - Análise das respostas de questões envolvendo os três tipos de crimes analisados na pesquisa}

\begin{tabular}{|c|c|c|c|c|c|c|c|}
\hline \multirow{3}{*}{ Tipo de crime } & \multicolumn{7}{|c|}{ \% Vítimas } \\
\hline & \multicolumn{2}{|c|}{ Gênero } & \multicolumn{2}{|c|}{ LGBT+ } & \multicolumn{2}{|c|}{ Etnia } & \multirow{2}{*}{ Total } \\
\hline & Fem & Masc & Sim & Não & $\mathrm{Br}$ & $\mathrm{NBr}$ & \\
\hline a. abuso ou assédio sexual & 71,3 & 18,8 & 32,5 & 57,5 & 66,3 & 26,3 & 17,3 \\
\hline \% de vítimas no próprio grupo & 26,5 & 8,2 & 31,7 & 14,2 & 16,5 & 21,4 & - \\
\hline $\begin{array}{l}\text { \% de vítimas do próprio grupo } \\
\text { que denunciou o crime }\end{array}$ & 22,8 & 13,3 & 23,0 & 19,6 & 20,8 & 19,0 & 20,0 \\
\hline $\begin{array}{l}\text { b. outros crimes de potencial } \\
\text { gravidade (assalto, estupro) }\end{array}$ & 51,2 & 39,5 & 21,0 & 72,1 & 72,1 & 21,0 & 9,3 \\
\hline \% de vítimas no próprio grupo & 10,2 & 8,2 & 11,0 & 9,6 & 9,6 & 10,0 & - \\
\hline $\begin{array}{l}\% \text { de vítimas do próprio grupo } \\
\text { que denunciou o crime }\end{array}$ & 43,5 & 53,0 & 11,1 & 59,4 & 53,1 & 33,3 & 45,5 \\
\hline c. roubo / batedor de carteira & 46,4 & 46,4 & 28,6 & 67,9 & 78,6 & 14,3 & 6,0 \\
\hline \% de vítimas no próprio grupo & 6,0 & 6,6 & 9,8 & 5,9 & 6,8 & 4,4 & - \\
\hline $\begin{array}{l}\text { \% de vítimas do próprio grupo } \\
\text { que denunciou o crime }\end{array}$ & 29,4 & 50,0 & 25,0 & 46,4 & 46,4 & 25,0 & 40,5 \\
\hline
\end{tabular}

Fonte: Pesquisa de Campo

Conforme os dados da Tabela 2 observa-se que o crime de abuso e assédio sexual ocorre mais do que outros tipos de crime, com taxa de $17,3 \%$ entre todos os participantes, contra $9,3 \%$ e $6,0 \%$ dos outros dois tipos de crimes, respectivamente. Vale ressaltar que a questão da vitimização foi avaliada somente para o caso de uso do sistema de transporte público e não no caso dos demais modais ou em caso de percursos realizados a pé.

De maneira geral, entre as vítimas, a porcentagem maior sempre é do sexo feminino, principalmente quando se trata do abuso ou assédio sexual (71,3\%). Esta porcentagem destaca-se ainda mais ao se observar a situação de equilíbrio existente entre as proporções de homens e mulheres da amostra (Tabela 1). Na realidade, deve-se destacar que $71,3 \%$ é o patamar mínimo das vítimas do sexo feminino. Este percentual ainda pode ser maior, pois corresponde a somente um dos Estudos Geográficos, Rio Claro, 17(1): 175-195, jan./jun. 2019 (ISSN 1678-698X) http://www.periodicos.rc.biblioteca.unesp.br/index.php/estgeo 
crimes analisados (abuso ou assédio sexual). Neste estudo não foi avaliada a somatória das respostas independentes dos três tipos de crimes. Mesmo assim, este percentual representa uma realidade preocupante das estudantes do sexo feminino.

Analisando as taxas de vitimização e a sua distribuição por gênero, por grupo LGBT+ e por etnia dos estudantes, os dados da Tabela 2 mostram que, no caso do crime de abuso e assédio sexual, os grupos mais vulneráveis são, em ordem, os LGBT+ com $31,7 \%$ de vítimas ( $120 \%$ a mais que os não-LGBT+), as mulheres com $26,5 \%$ de vítimas $(220 \%$ a mais que os homens) e os não-brancos com $21,4 \%$ de vítimas (30\% a mais que os brancos). Esta discrepância não se observa em relação a outros tipos de crimes.

Outro ponto que merece destaque é a relação dos vitimados no crime de roubo/batedor de carteira, em relação ao grupo étnico, onde os brancos são mais vítimas do que os não-brancos (6,8\% contra $4,4 \%)$, invertendo a situação no caso de outros dois crimes, com destaque para vítimas não-brancos de abuso ou assédio sexual $(21,4 \%)$.

A Tabela 3 apresenta o resultado das respostas dos estudantes sobre o que eles consideram como um problema significativo ao usar o transporte público. No total 178 estudantes responderam esta questão. Os itens estão ordenados, de forma decrescente, pelo número total de indivíduos que assinalaram cada item, mostrados na coluna "Respostas". Nesta coluna, a soma das respostas para as opções "no ônibus" e "no ponto de ônibus" sempre ultrapassa o total de respostas para o item (marcado em negrito), pois algumas pessoas marcaram ambas as opções. As demais colunas mostram a distribuição das respostas por diversos grupos, considerando o gênero, etnia e se o indivíduo pertence ou não ao grupo LGBT+. Nestas colunas, a soma das respostas das duas colunas de cada subgrupo não é igual ao total das respostas para cada item, pois, algumas pessoas deixaram de especificar o seu gênero, etnia ou opção sexual.

Assim, observa-se que os cinco problemas mais significativos, considerados pelos estudantes são: "falta de vigilância/local vazio", "iluminação precária", "furto de carteira/bolsa", "roubo" e "isolamento", todos com maior peso para o ponto de ônibus. Curiosamente, pode-se observar que, no transporte público, os estudantes se preocupam mais com o vandalismo e lixo do que com o assédio sexual.

Estudos Geográficos, Rio Claro, 17(1): 175-195, jan./jun. $2019 \quad$ (ISSN 1678-698X) http://www.periodicos.rc.biblioteca.unesp.br/index.php/estgeo 
Tabela 3 - Respostas sobre a questão: Quais das alternativas você considera como um problema significativo ao usar o ônibus e/ou no ponto de ônibus? (assinale todas que se aplicam)

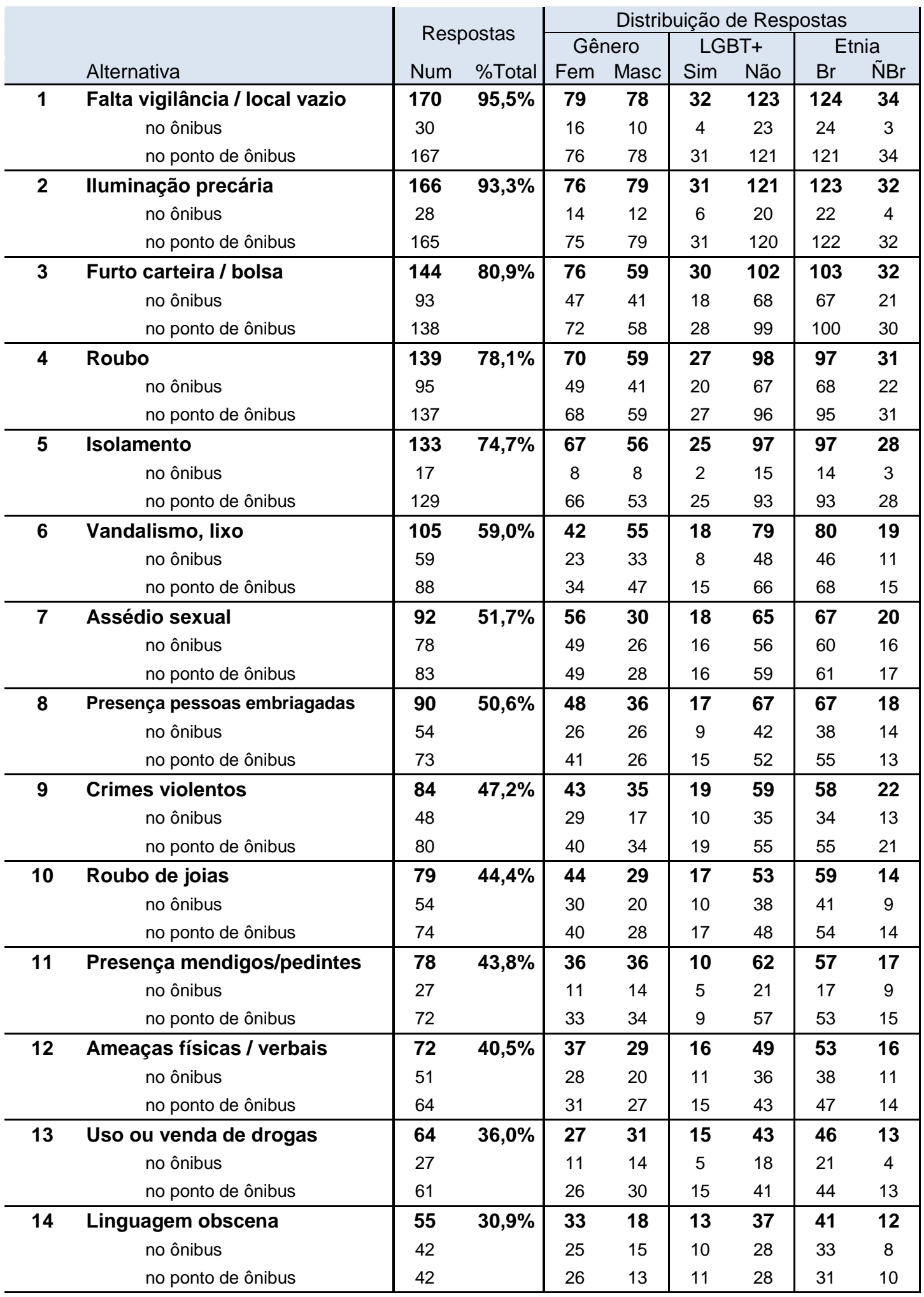

Fonte: Pesquisa de Campo

Considerando a questão do gênero, os dados apresentam alguns pontos de reflexão. Para as mulheres os problemas mais significativos são, em ordem, "assédio sexual", tanto no ônibus, como no ponto de ônibus (53,3\% - 49 do total de Estudos Geográficos, Rio Claro, 17(1): 175-195, jan./jun. 2019 (ISSN 1678-698X) http://www.periodicos.rc.biblioteca.unesp.br/index.php/estgeo 
92 indivíduos que assinalaram esta opção). Seguido de "roubo de joias" (50,6\%), "furto de carteira/bolsa" (50\%), "isolamento" (49,6\%), "roubo" (48,9\%) e "crimes violentos" (47,6\%), estes todos nos pontos de ônibus. Enquanto para os homens os problemas mais significativos são, em ordem, "iluminação precária" (47,6\%), "uso ou venda de drogas" (46,9\%), "falta de vigilância" (45,9\%), "vandalismo, lixo" $(44,8 \%)$, "presença de mendigos" $(43,6)$ e "roubo" $(42,5 \%)$, todos relacionados também aos pontos de ônibus.

É importante notar que para todos os problemas citados, o número de respostas é maior quando relacionado ao ponto de ônibus, exceto o problema de "assédio sexual" no caso de mulheres e o problema de "presença de pessoas embriagadas", no caso dos homens, que apresentam mesmas porcentagens tanto em relação ao ônibus como ao ponto de ônibus.

\section{INFLUÊNCIAS DO MEIO CULTURAL E URBANO}

Inicialmente, destaca-se que o índice do uso de transporte público pelos estudantes da UNESP em Rio Claro, para o seu deslocamento até o Campus Universitário, é relativamente baixo. Do total de estudantes que participaram da pesquisa somente $8 \%$ declararam usar mais frequentemente o ônibus no seu trajeto até a universidade, $11 \%$ disseram que usam ocasionalmente, $19 \%$ usam raramente e cerca de $62 \%$ nunca usam o ônibus para ir ao Campus.

Entretanto, cerca de $44 \%$ de todos os participantes optaram por responder as perguntas sobre o uso do ônibus. Isto indica que se no momento não utilizam o ônibus para o seu deslocamento até a universidade, já o fizeram no passado ou utilizam este meio de transporte público para outros trajetos, o que lhes deu condições suficientes para responder a estas perguntas. Do total de estudantes que responderam a este bloco de perguntas, $58,3 \%$ relataram que se sentem sempre ou frequentemente seguros ao utilizar o ônibus, enquanto $32,8 \%$ responderam que se sentem seguros às vezes e $8,7 \%$ expressaram que nunca ou raramente se sentem seguros ao utilizar o ônibus.

A razão do baixo índice de uso do ônibus por estudantes da UNESP pode ser relacionada a vários fatores do ambiente urbano de Rio Claro. Primeiro, porque o Campus da UNESP em Rio Claro, se localiza em um bairro residencial e a grande maioria dos estudantes mora próximo à universidade, pois 67\% afirmaram que gastam menos de 15 minutos para chegar à universidade. Em segundo lugar, porque, em função da topografia plana da cidade, quase a metade dos participantes da pesquisa utiliza bicicleta para a sua locomoção urbana $(48,2 \%)$. Terceiro, porque em função da baixa frequência de viagens de ônibus e da má distribuição das rotas em direção à universidade, o tempo de viagem até a universidade costuma ser muito demorado (motivo alegado por cerca de $49 \%$ dos estudantes). Além disso, o custo da passagem também é considerado elevado para cerca de $46 \%$ dos estudantes que responderam esta questão.

Por outro lado, os estudantes relataram uma significativa sensação de insegurança no ponto de ônibus e no trajeto até o ponto de ônibus, principalmente no período noturno, quando cerca de $73 \%$ dos estudantes se sentem inseguros ao usar o ônibus (contra $30 \%$ no período diurno). Este sentimento pode ter a sua explicação no fato destes lugares serem ambientes públicos em uma cidade com altas taxas de criminalidade e, portanto, sujeitos a toda sorte de violência urbana.

Estudos Geográficos, Rio Claro, 17(1): 175-195, jan./jun. 2019 (ISSN 1678-698X) http://www.periodicos.rc.biblioteca.unesp.br/index.php/estgeo 
A Tabela 4 mostra os fatores mais destacados pelos estudantes como impedimentos de utilizar o ônibus mais frequentemente. Os fatores mais marcantes foram o tempo demorado da viagem (49,5\%), o custo da passagem (45,9\%), o medo de serem vítimas de um crime no ponto de ônibus ou no trajeto até o ponto de ônibus (36,2\%), o medo de sofrerem algum tipo de abuso ou assédio enquanto estão no ônibus (25\%) e a falta de informações sobre os horários de ônibus $(25,0 \%)$.

\section{Tabela 4 - Respostas sobre a questão: Das seguintes alternativas, quais impedem você de usar ônibus mais frequentemente? \\ (assinale todas que se aplicam)}

\begin{tabular}{|c|c|c|c|c|c|c|c|}
\hline \multirow[b]{3}{*}{ Alternativas } & \multirow[b]{3}{*}{ \%Total } & \multicolumn{6}{|c|}{$\%$} \\
\hline & & \multicolumn{2}{|c|}{ Gênero } & \multicolumn{2}{|c|}{ LGBT+ } & \multicolumn{2}{|c|}{ Etnia } \\
\hline & & Fem & Masc & Sim & Não & $\mathrm{Br}$ & $\mathrm{N} B r$ \\
\hline Tempo de viagem demorado & 49,5 & 47,4 & 46,4 & 21,7 & 70,1 & 75,2 & 20,6 \\
\hline Custo da passagem/bilhete & 45,9 & 45,5 & 47,8 & 17,8 & 76,6 & 72,2 & 24,4 \\
\hline $\begin{array}{l}\text { Medo de abuso ou assédio enquanto caminha e/ou } \\
\text { espera por ônibus }\end{array}$ & 36,2 & 66,2 & 25,3 & 15,5 & 76,0 & 73,2 & 22,5 \\
\hline Medo de abuso ou assédio enquanto está no ônibus & 25,0 & 77,6 & 16,3 & 18,3 & 73,4 & 73,5 & 22,4 \\
\hline Falta de informações sobre horários de ônibus & 25,0 & 44,9 & 53,0 & 24,5 & 69,4 & 71,4 & 26,5 \\
\hline Serviço não confiável ou não frequente de ônibus & 19,9 & 43,6 & 56,4 & 12,8 & 82,0 & 79,5 & 10,2 \\
\hline Medo de assédio sexual no ônibus & 18,8 & 91,9 & 5,4 & 18,9 & 78,4 & 75,7 & 21,6 \\
\hline Serviços superlotados & 15,8 & 29,0 & 58,0 & 25,8 & 64,5 & 67,7 & 22,6 \\
\hline Muitas trocas de ônibus (baldeação) & 14,5 & 53,8 & 38,4 & 19,2 & 76,9 & 80,8 & 19,2 \\
\hline Ambiente sujo no ônibus (lixo, pichação) & 10,7 & 42,9 & 52,4 & 16,7 & 85,7 & 66,7 & 33,3 \\
\hline $\begin{array}{l}\text { Preocupação em relação ao comportamento } \\
\text { antissocial de outros }\end{array}$ & 10,2 & 50,0 & 35,0 & 35,0 & 60,0 & 75,0 & 20,0 \\
\hline Medo de acidentes de trânsito & 8,1 & 62,5 & 25,0 & 6,2 & 75,0 & 50,0 & 37,5 \\
\hline $\begin{array}{l}\text { Ambiente sujo durante a caminhada até o ponto de } \\
\text { ônibus }\end{array}$ & 2,0 & 25,0 & 75,0 & 25,0 & 75,0 & 100,0 & 0.0 \\
\hline
\end{tabular}

Fonte: Pesquisa de Campo

Entretanto, para as mulheres os maiores impedimentos foram o medo de assédio sexual no ônibus (91,9\%), medo de outro tipo de abuso ou assédio enquanto está no ônibus $(77,6)$ e o medo de abuso ou assédio enquanto caminha e/ou espera por ônibus $(66,2 \%)$. Já para os homens, os maiores impedimentos foram o ambiente sujo durante a caminhada até o ponto de ônibus $(75,0 \%)$, serviços superlotados (58\%) e o serviço não confiável ou não frequente de ônibus $(56,4 \%)$. 0 assédio contra mulheres, a insegurança e a superlotação dos ônibus também foram elencados como sérios problemas do sistema, em uma pesquisa realizada junto aos usuários do transporte público em Piracicaba, SP (ASSENCIO; BITENCOURT, 2018; EPTV-G1, 2018).

Como se pode observar, as deficiências relacionadas ao gerenciamento do serviço de transporte público em Rio Claro são muito citadas pelos estudantes como importantes impedimentos para o uso mais frequente de ônibus por parte deles.

As sugestões dadas pelos estudantes para tornar a viagem de ônibus mais segura, por sua vez, envolvem também, de forma mais decisiva, fatores relacionados ao ambiente externo da jornada de ônibus, como melhor iluminação, policiamento, instalação de câmeras, e tabela digital de horários, nos pontos de ônibus. Exceto a instalação de câmeras nos ônibus, todas as outras sugestões prioritárias estão relacionadas aos pontos de ônibus, isto é, aos espaços do ambiente urbano.

Estudos Geográficos, Rio Claro, 17(1): 175-195, jan./jun. 2019 (ISSN 1678-698X) http://www.periodicos.rc.biblioteca.unesp.br/index.php/estgeo 
De fato, como visto anteriormente (Tabela 3), isto é confirmado pelos participantes quando assinalam, como problemas mais significativos, alguns fatores relacionados aos pontos de ônibus, tais como a iluminação precária, a falta de vigilância e o isolamento, que receberam porcentagens mais altas para os pontos de ônibus do que para o interior do veículo.

Destaca-se novamente, como foi analisado na Tabela 2, que a grande maioria dos estudantes da UNESP em Rio Claro, relatou não ter sido vítima de qualquer tipo de violência no sistema de transporte público (82,7\% não sofreram abuso ou assédio sexual, $90,7 \%$ não sofreram outros crimes de potencial gravidade e $94,0 \%$ não foram vítimas de roubo). Além disso, mais de $63 \%$ dos participantes relataram também não conhecer alguém que tenha sido vítima.

Por outro lado, apesar de apenas $19 \%$ dos estudantes usarem ônibus de alguma forma, mais de $32 \%$ sentem a necessidade de tomar alguma precaução ao usar o ônibus e neste caso, novamente, as precauções mais citadas se referem aos fatores externos ao ônibus, ou seja, o ambiente urbano (esperar o ônibus somente em locais bem iluminados - 56,6\%; evitar determinados pontos de ônibus - 55,9\%; viajar somente durante dia - 43,4\%; evitar carregar bolsas ou carteiras - $42 \%$ ).

Outra constatação importante, que pode ser observada na Tabela 2, é o elevado índice de subnotificação de delitos (a não denúncia). Do total de estudantes vitimados no crime de abuso ou assédio sexual, mais de $80 \%$ não denunciaram os crimes sofridos. No caso de outros crimes de potencial gravidade, $54,5 \%$ também não fizeram o registro oficial dos crimes sofridos, sendo que neste caso a metade das vítimas relatou o fato para a família e/ou para amigos. Entre os estudantes que sofreram algum tipo de roubo, cerca de $60 \%$ não procuraram as autoridades para denunciar o crime sofrido. Este comportamento pode ser atribuído ao resultado do ambiente sociocultural do país, onde há um elevado índice de violência urbana, aliado à descrença da população em relação à polícia e ao sistema judiciário (DANTAS, 2015).

Entretanto, é fundamental que as vítimas denunciem os crimes sofridos, independente do grau de sua criticidade, pois, a quantificação e qualificação dos delitos denunciados permitem ao poder público elaborar estratégias preventivas e combativas para reduzir o nível de importunação sexual.

A questão da subnotificação é muito discutida na literatura. Machado (2017) afirma que a subnotificação dos atos ocorridos perpetua a invisibilidade da violência na sociedade. Um interessante trabalho sobre o assunto é de Alcântara et al. (2016), onde são listados como causas da subnotificação: o constrangimento da vítima, na delegacia, quando, muitas vezes, tem que ficar frente a frente com o agressor, enquanto aguarda atendimento; certas perguntas feitas pelos policiais que naturalizam a violência, buscando uma justificativa para o crime; e a sensação de impunidade dos agressores.

Analisando os dados da Tabela 2 no prisma do gênero, observa-se que $71,3 \%$ dos estudantes vítimas do crime de abuso ou assédio sexual são do sexo feminino e $18,8 \%$ do sexo masculino. Entre as vítimas mulheres desse tipo de crime, somente $22,8 \%$ denunciaram o crime sofrido. Enquanto, entre os homens esse percentual é ainda menor (13,3\%). Isto reflete as características socioculturais da sociedade brasileira, onde os níveis alarmantes de violência contra mulher têm relação direta com o machismo. Uma análise mais detalhada dos resultados desta pesquisa sobre a questão da subnotificação está sendo elaborada e oportunamente será publicada.

Estudos Geográficos, Rio Claro, 17(1): 175-195, jan./jun. 2019 (ISSN 1678-698X) http://www.periodicos.rc.biblioteca.unesp.br/index.php/estgeo 
Tabela 5 - Respostas sobre a questão: Você pode indicar o porquê de não ter denunciado o crime de abuso ou violência sexual? (assinale todas que se aplicam)

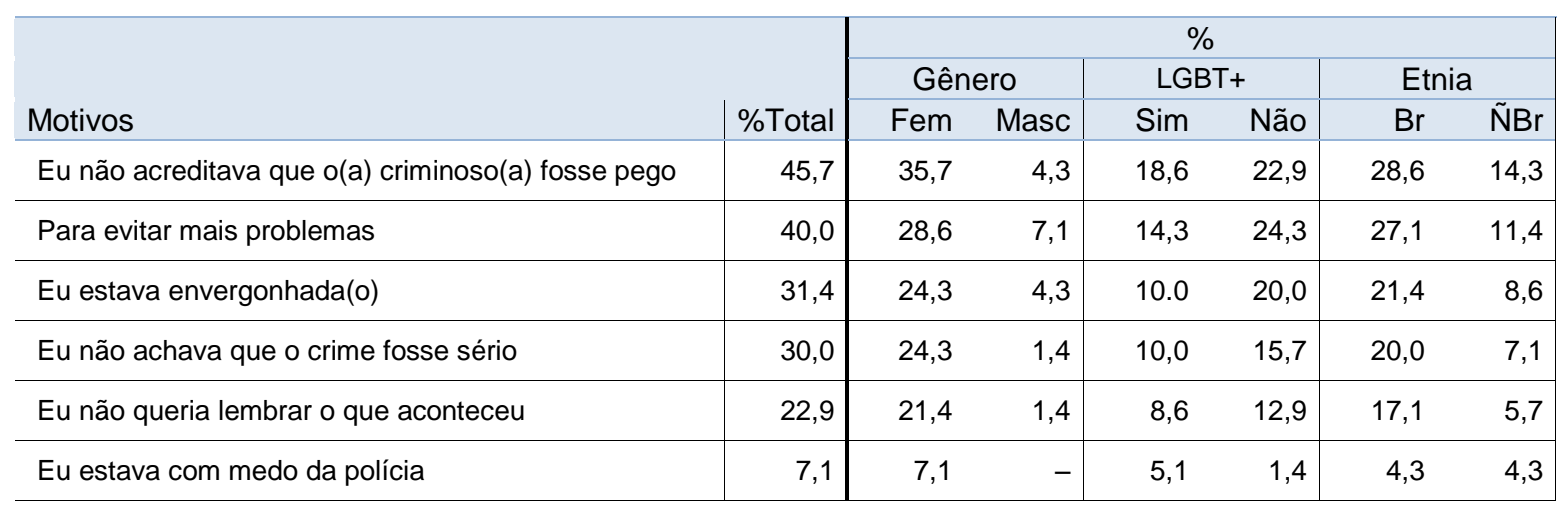

Fonte: Pesquisa de Campo

A tabela 5 mostra os dados relacionados às motivações da vítimas em não denunciar o crime sofrido. Aproximadamente $45,7 \%$ das vítimas de abuso ou violência sexual não denunciaram o crime por não acreditar que o criminoso seria pego, enquanto $40 \%$ declararam não terem denunciado a agressão sofrida para evitar mais problemas. Além disso, cerca de $31 \%$ não denunciaram o delito porque se sentiam envergonhados e $30 \%$ não denunciaram porque não o consideravam sério.

Ao se analisar a questão da subnotificação, considerando o gênero das vítimas, observa-se que este comportamento ocorre majoritariamente entre as mulheres. Os resultados reforçam a tese de que este comportamento é reflexo de uma cultura desfavorável à mulher, com fortes traços do machismo. Para combater esta situação são necessárias políticas públicas coerentes e consistentes de valorização da mulher e massivas campanhas educacionais inteligentes e persistentes.

\section{REFLEXOS DA INFRAESTRUTURA DE TRANSPORTE}

A análise dos resultados obtidos na pesquisa permite supor que algumas melhorias de infraestrutura e pequenos ajustes de políticas públicas no sistema de transporte público podem contribuir para aumentar a sensação de segurança de seus usuários. Para discutir isto é necessário retomar, novamente, a análise de alguns dados da Tabela 3.

É marcante observar que os estudantes têm maior sensação de insegurança quando ficam esperando o transporte no ponto de ônibus do que quando estão viajando dentro do ônibus. Os problemas mais citados por eles estão mais associados aos pontos de ônibus do que ao próprio ônibus. Isto sugere que o medo dos estudantes seja majoritariamente em função das condições precárias da infraestrutura dos pontos de ônibus, bem como da baixa eficiência de políticas públicas de segurança relacionadas a estes locais.

Por outro lado, pode-se dizer que as condições precárias da infraestrutura dos pontos de ônibus contribuem para a alta frequência de furtos (138 indicações) e de roubos (137 indicações) nestes lugares, os quais representam os atos de violência mais reclamados pelos estudantes. Certamente políticas do poder público que promovam melhorias na infraestrutura dos pontos de ônibus devem resultar em Estudos Geográficos, Rio Claro, 17(1): 175-195, jan./jun. 2019 (ISSN 1678-698X) http://www.periodicos.rc.biblioteca.unesp.br/index.php/estgeo 
diminuição da ocorrência de furtos e roubos e aumentar a sensação de segurança dos usuários do sistema de transporte público.

Neste sentido, iniciativas governamentais ou em parceria com o setor privado podem coibir as ações de criminosos e diminuir o problema de furto de carteira/bolsa ou de roubo, bem como de outros crimes contra os usuários do transporte público e da população em geral. Dentre essas melhorias pode-se indicar: implantar ou melhorar a iluminação nos pontos de ônibus e no seu entorno; resolver o problema de isolamento, deslocando alguns pontos de ônibus para lugares menos isolados ou implementar melhorias urbanas, como por exemplo, incentivos para melhorias imobiliárias, que eliminem a questão do isolamento dos pontos de ônibus.

Ao analisar os problemas citados pelos estudantes, que ocorrem no interior do ônibus, observa-se que dois deles se destacam com alta predominância, citados por mais de $50 \%$ dos estudantes, o roubo (95 indicações - 53\%) e o furto de carteira/bolsa (93 indicações - 52\%), ainda que com níveis inferiores do que no caso dos pontos de ônibus. Estes problemas poderiam ser mitigados com a instalação de câmeras no interior dos ônibus. Esta medida, relativamente simples e econômica, poderia também contribuir para amenizar até os problemas menos citados, relacionados ao ônibus, tais como o isolamento, presença de mendigos/pedintes, uso ou venda de drogas e a falta de vigilância.

Neste estudo analisaram-se também os diferentes tipos de assédio ou agressão sexual e as suas ocorrências tanto no ônibus, como no ponto de ônibus ou no trajeto do ponto de ônibus. Os dados desta análise são mostrados na Tabela 6, onde os delitos referem-se às ocorrências dos últimos três anos e estão ordenados pela frequência total de indicações de cada um. Ressalta-se que 117 estudantes responderam a pergunta correspondente a esta análise, dos quais 73 foram do sexo feminino e 39 do sexo masculino (1 estudante preferiu não se classificar, 1 se declarou transexual e 3 não especificaram o seu gênero).

Dentre os resultados apresentados na Tabela 6 , os três delitos mais citados ocorrem com maior frequência no caminho para o ponto de ônibus ou no ponto de ônibus, embora as suas ocorrências não possam ser desconsideradas durante a viagem no ônibus. Por outro lado, o problema de "ser tocada(o) de forma inapropriada" embora não esteja entre os mais citados, ocorre com maior frequência dentro do ônibus, provavelmente pela proximidade existente entre os passageiros, principalmente se o veículo estiver com lotação acima da desejada. Ao analisar a ocorrência dos demais tipos de delitos, observa-se que cada um deles apresenta um total de indicações próximo, tanto no ponto de ônibus, quanto na ida ao ponto ou dentro do ônibus.

Estudos Geográficos, Rio Claro, 17(1): 175-195, jan./jun. 2019 (ISSN 1678-698X) http://www.periodicos.rc.biblioteca.unesp.br/index.php/estgeo 


\section{Tabela 6 - Respostas sobre a questão: Nos últimos 3 anos, você vivenciou algumas das seguintes situações enquanto caminhava para e/ou esperava no ponto de ônibus ou enquanto estava no ônibus? (assinale com $X$ todas que se aplicam)}

\begin{tabular}{|c|c|c|c|c|}
\hline \multirow[b]{2}{*}{$\begin{array}{l}\text { Tipo de assédio/agressão sexual } \\
\text { Ordenado pelo total de indicações }\end{array}$} & \multicolumn{4}{|c|}{ № de Indicações } \\
\hline & Total & $\begin{array}{c}\text { No } \\
\text { ônibus }\end{array}$ & $\begin{array}{l}\text { No ponto } \\
\text { de ônibus }\end{array}$ & $\begin{array}{l}\text { No trajeto } \\
\text { do ponto } \\
\text { de ônibus }\end{array}$ \\
\hline Ser chamada(o) de gatinha(o), docinho, querida(o), amor, etc. & 92 & 52 & 70 & 65 \\
\hline Ser perseguida(o) por um estranho & 81 & 19 & 31 & 66 \\
\hline Assobio & 77 & 38 & 55 & 56 \\
\hline Receber olhares ou gestos sexuais indesejados & 70 & 48 & 51 & 42 \\
\hline Receber comentários sexuais (sobre vestimenta, aparência, etc.) & 55 & 36 & 42 & 40 \\
\hline Uso de linguagem obscena/abusiva & 46 & 34 & 29 & 31 \\
\hline Provocações/observações sexuais indesejadas & 44 & 26 & 31 & 26 \\
\hline Alguém fazendo som de beijo & 33 & 16 & 22 & 23 \\
\hline Ser tocada(o) de forma inapropriada & 31 & 27 & 5 & 3 \\
\hline Exibicionismo indecente & 23 & 15 & 13 & 10 \\
\hline Perguntas pessoais sobre sua vida sexual & 20 & 10 & 14 & 11 \\
\hline Alguém puxar ou brincar com seus cabelos & 19 & 14 & 11 & 7 \\
\hline Ser convidada(o) por um estranho a fazer sexo & 16 & 6 & 7 & 7 \\
\hline Masturbação em público & 15 & 8 & 8 & 1 \\
\hline Exibição de imagens pornográficas & 14 & 8 & 5 & 1 \\
\hline Ser beijada(o) por um estranho & 7 & 3 & 2 & 4 \\
\hline
\end{tabular}

Fonte: Pesquisa de Campo

Dentre os cinco tipos de importunações de cunho sexual, mais citados pelos estudantes, três podem ser considerados de potencial menos agressivos, "ser chamada(o) de gatinha(o), docinho, querida(o), amor, etc.", "assobio" e "receber olhares ou gestos sexuais indesejados", um de agressividade um pouco maior "receber comentários sexuais (sobre vestimenta, aparência, etc.)" e um de agressividade mais crítica "Ser perseguida(o) por um estranho". Ressalta-se que esta última ocorre preponderantemente no caminho para o ponto de ônibus ou enquanto aguarda no ponto de ônibus.

Acredita-se que os casos de potencial menos agressivo possam ser mais facilmente reduzidos por meio da conscientização dos usuários de transporte público, bem como da população em geral. Campanhas educacionais mais simples, com foco nestas questões, podem contribuir para a diminuição de ofensas que incomodam muito os usuários e se encontram entre os mais citados pelos estudantes. Visando maior efetividade, estas campanhas precisariam ser massivas e realizadas nas escolas, para atingir crianças e adolescentes. Além disso, as demais faixas etárias da população também deveriam ser alcançadas simultaneamente por campanhas nas mídias de comunicação tradicionais, como jornal, televisão e rádio, bem como a internet e diretamente nos ônibus e nos pontos de ônibus.

Estudos Geográficos, Rio Claro, 17(1): 175-195, jan./jun. $2019 \quad$ (ISSN 1678-698X) http://www.periodicos.rc.biblioteca.unesp.br/index.php/estgeo 


\section{CONCLUSÕES}

As análises de dados sobre os resultados da pesquisa permitem observações bastante interessantes. A primeira delas é observar que a porcentagem dos estudantes que tem medo de usar o ônibus é muito elevada, chegando a $73 \%$ no período noturno e $30 \%$ no período diurno, apesar da baixíssima frequência de uso do ônibus declarada por eles.

Examinando as respostas das perguntas que envolvem a questão da violência, observa-se que $25,8 \%$ dos alunos relataram ter vivenciado pelo menos um dos três tipos de violência abordados na pesquisa, onde o de abuso ou assédio sexual foi mencionado com maior incidência. Em geral, o gênero feminino é a maior vítima dos três tipos de crime analisados, chegando a $73 \%$ das vítimas no caso de abuso ou assédio sexual. Talvez isto seja a razão porque a maioria de usuários de carro, de transporte por aplicativo e de motocicletas são mulheres, tentando evitar sua vitimização na mobilidade urbana.

De qualquer forma, a baixa sensação de segurança sentida pelos estudantes no transporte público tem relação direta com os elevados índices de violência, que por sua vez podem estar relacionados com a sensação de impunidade que impera nas sociedades das cidades brasileiras (CARBONARI; LIMA, 2016; CARVALHO et al., 2018). Os problemas levantados nesta pesquisa por estudantes da UNESP são muito semelhantes aos resultados obtidos em outra pesquisa realizada pelo Observatório Cidadão de Piracicaba junto aos usuários de transporte público em Piracicaba, em parceria com o Laboratório de Planejamento Municipal do IGCE/UNESP (OBSERVATÓRIO CIDADÃO, 2018).

Em contraste ao uso do transporte público coletivo pelos estudantes está o transporte individual, onde $48,3 \%$ dos participantes da pesquisa afirmaram usar bicicleta frequentemente, $32,2 \%$ relataram usar carro ou moto frequentemente e $26,6 \%$ relataram usar taxi ou transporte por aplicativo. Isso impacta negativamente no trânsito local com o aumento da probabilidade de acidentes de trânsito, o que é confirmado pelas estatísticas, e ainda acarreta em outros problemas no sistema público de saúde e na sociedade como um todo, tendo efeitos negativos e sensíveis no orçamento do poder público.

A descrença da população no sistema jurídico brasileiro e a falta de efetividade na apuração dos crimes, associadas a algumas características socioculturais, contribuem para que uma grande parcela dos crimes não seja denunciada. Infelizmente, a subnotificação dificulta o planejamento de ações preventivas por parte das instituições de segurança pública, já que não se tem um mapeamento preciso das ocorrências de crime.

O Senado brasileiro propôs e foi sancionada em 24/09/2018 a Lei no 13.718 que, dentre outras coisas, tipifica o crime de importunação sexual. Como consequência, espera-se que doravante haja uma diminuição dos delitos de assédio sexual nos ônibus, já que dentre outras coisas, esta lei possibilita enquadrar homens que assediam sexualmente mulheres dentro do transporte público, algo que até então não era possível juridicamente.

Por meio desta pesquisa em Rio Claro observou-se que os maiores problemas apontados pelos estudantes, que contribuem significativamente para gerar sensação de insegurança nos usuários do transporte público, principalmente no período noturno, tanto no ponto de ônibus quanto no percurso ao ponto do ônibus, referem-se a questões simples de infraestrutura e de segurança em ambientes externos ao ônibus. Entretanto, esses ambientes externos ao ônibus são

Estudos Geográficos, Rio Claro, 17(1): 175-195, jan./jun. $2019 \quad$ (ISSN 1678-698X) http://www.periodicos.rc.biblioteca.unesp.br/index.php/estgeo 
os mesmos que outros estudantes também frequentam, ao se deslocarem a pé ou de bicicleta, e sendo assim, podem estar sujeitos aos mesmos tipos de violência relatados pelos usuários de ônibus.

Acredita-se que esta situação possa ser amenizada, substancialmente, com um investimento moderado de recursos financeiros do poder público ou com parcerias do setor privado, pois, observou-se que na grande maioria dos casos os problemas representam simples falhas de infraestrutura dos pontos de ônibus ou um pequeno desajuste das políticas públicas de transporte, que não exigem investimentos volumosos.

\section{REFERÊNCIAS}

ALCANTARA, M.C.M., et al., Subnotificação e Invisibilidade da Violência contra a Mulher. Revista Médica de Minas Gerais, 26 (Supl 8), S313-S317, 2016.

AMÂNCIO, T. Brasil tem 12 assassinatos de mulheres e 135 estupros por dia, mostra balanço. Folha de São Paulo - Cotidiano. 30/10/2017. Disponível em: https://www1.folha.uol.com.br/cotidiano/2017/10/1931609-brasil-registrou-135-

estupros-e-12-assassinatos-de-mulheres-por-dia-em-2016.shtml. Acesso em: 29 set. 2018.

ASSENCIO, C.; BITENCOURT, R. Transporte Público: Comportamento de motoristas agrada passageiros, insegurança e lotação são motivos de reprovação. Observatório Cidadão de Piracicaba, Notícias 20/11/2018. Disponível em: http://www.observatoriopiracicaba.org.br/noticias/245/transporte-publicocomportamento-de-motoristas-agrada-passageiros-inseguranca-e-lotacao-saomotivos-de-reprovacao. Acesso em: 15 jul. 2019.

BBC-NEWS. Exposição na Bélgica traz roupas de vítimas de estupro para romper mito de 'culpa da mulher'. BBC Brasil, 2018. Disponível em: https://www.bbc.com/portuguese/geral-42643532. Acesso em: 29 mar. 2019.

CABRAL JUNIOR, M.; GAMBA, C.T.C. Ordenamento Territorial Geomineiro (OTGM) do polo mínero-cerâmico de Santa Gertrudes - SP: um instrumento de planejamento e gestão para garantir o suprimento sustentável de recursos minerais. Revista de Gestão Ambiental e Sustentabilidade, v. 6, n. 3, p. 54-73, set-dez 2017.

CARBONARI, F.; LIMA, R.S. Cidades seguras. In: COSTA, M. A. (org.) O Estatuto da Cidade e a Habitat III: um balanço de quinze anos da política urbana no Brasil e a nova agenda urbana. Brasília: IPEA, cap. 3, p. 85-106, 2016.

CARNEIRO, J.G.V. A Violência no Espaço Urbano: uma Crítica Benjaminiana. Estudo de Caso da Cidade de Rio Claro. 2013. Tese (Doutorado em Geografia) Instituto de Geociências e Ciências Exatas, Universidade Estadual paulista, Rio Claro (IGCE/UNESP).

CARNEIRO, J.G.V.; CARNEIRO, M.C.V.S.; GOVONE, J.S.; NOURANI, F.; PIÃO, A.C.S. Diagnóstico da violência e da criminalidade no município de Rio Claro / SP. DEMAC/UNESP, Rio Claro, 2009.

Estudos Geográficos, Rio Claro, 17(1): 175-195, jan./jun. 2019 (ISSN 1678-698X) http://www.periodicos.rc.biblioteca.unesp.br/index.php/estgeo 
CARVALHO, C.O.; GRASSI, K.; GRAZIANO SOBRINHO, S.F.C. (org.). Vidas urbanas e a vida nas cidades: regramentos urbanos, ambientais, seletividade $e$ violência. Universidade de Caxias do Sul. Caxias do Sul, RS: EDUCS, 2018. Disponível em: https://www.ucs.br/site/midia/arquivos/ebook-vidas-urbanas.pdf. Acesso em: 22/03/2019.

CARVALHO, J.R.; OLIVEIRA, V.H., Violência doméstica e seu impacto no mercado de trabalho e na produtividade das mulheres. 2017. Universidade Federal do Ceará. Programa de Pós-Graduação em Economia. Relatório Executivo II - Primeira Onda.

CECCATO, V. Women's transit safety: making connections and defining future directions in research and practice. Crime Prevention and Community Safety, n. 19, p. 276-287, 2017. Macmillan Publishers. doi 10.1057/s41300-017-0032-5.

CECCATO, V.; Paz, Y. Crime in São Paulo's metro system: sexual crimes against women. Crime Prevention and Community Safety, 19(3), p. 211-226, 2017. doi 10.1057/s41300-017-0027-2.

CERQUEIRA, D. et al. Atlas da violência 2017. Instituto de Pesquisa Econômica e Aplicada - IPEA. Rio de Janeiro, 2017. Disponível em: http://www.ipea.gov.br/atlasviolencia/arquivos/downloads/8891-1250170602atlasdaviolencia2017.pdf Acesso em: 18 set. 2018.

CERQUEIRA, D. et al. Atlas da violência 2018. Instituto de Pesquisa Econômica e Aplicada - IPEA. Rio de Janeiro, 2018. Disponível em: http://www.ipea.gov.br/atlasviolencia/arquivos/downloads/8626-7457-2852180604atlasdaviolencia2018.pdf Acesso em: 21 fev. 2019.

DANTAS, A.C. Mediação policial, segurança pública e segurança humana: uma abordagem reflexiva. Direito, Estado e Sociedade, n. 46, p. 72-100, 2015.

EPTV-G1. Para 69\% dos usuários, assédio contra mulheres é problema no transporte público de Piracicaba. Portal do G1 Piracicaba e Região, 2018. Disponível em: https://g1.globo.com/sp/piracicaba-regiao/noticia/2018/10/25/para-69dos-usuarios-assedio-contra-mulheres-e-problema-do-transporte-publico-depiracicaba.ghtml. Acesso em: 15 de jul. 2019.

GEKOSKI, A.; GRAY, J.M.; HORVATH, M.A.H.; EDWARDS, S.; EMIRALI, A.; ADLER, J.R. 'What Works' in Reducing Sexual Harassment and Sexual Offences on Public Transport Nationally and Internationally: A Rapid Evidence Assessment. London: British Transport Police and Department for Transport, 2015.

GROTTA, C.A.D. O transporte coletivo urbano em Rio Claro, SP. 2001. Tese (Doutorado em Geografia) Instituto de Geociências e Ciências Exatas, Universidade Estadual paulista, Rio Claro (IGCE/UNESP).

GRUPORIOCLAROSP. Exposição no Casarão da Cultura é prestigiada por juízes da comarca de Rio Claro. Portal do Grupo Rio Claro - SP, 2019. Disponível em:

Estudos Geográficos, Rio Claro, 17(1): 175-195, jan./jun. 2019 (ISSN 1678-698X) http://www.periodicos.rc.biblioteca.unesp.br/index.php/estgeo 
https://www.gruporioclarosp.com.br/exposicao-no-casarao-da-cultura-e-prestigiadapor-juizes-da-comarca-de-rio-claro/. Acesso em: 29 mar. 2019.

$\begin{array}{lccccc}\text { INSTITUTO } & \text { BRASILEIRO DE } & \text { GEOGRAFIA E ESTATÍSTICA (IBGE). Dados } \\ \text { Estatísticos } & \text { de } & \text { Rio Claro. } & \text { 2018. Disponível em: }\end{array}$ https://cidades.ibge.gov.br/brasil/sp/rio-claro/panorama. Acesso em: 10 mar. 2019.

LOUKAITOU-SIDERIS, A. Fear and safety in transit environments from the women's perspective. Security Journal, n. 27, p. 242-256, 2014. doi:10.1057/sj.2014.9

MACHADO L. Casos aumentam, mas estupro ainda é crime subnotificado. Portal do G1SP. Disponível em: https://g1.globo.com/sao-paulo/noticia/saiba-o-quecaracteriza-crime-de-estupro-e-como-fazer-para-denunciar.ghtml. 2017. Acesso em: 03 maio 2019.

MELLO, R. C. A. Análise do aporte de sedimentos na bacia hidrográfica do córrego Assistência, SP: Caso do Polo Cerâmico de Santa Gertrudes. Dissertação (Mestrado em Geociências e Meio Ambiente), Instituto de Geociências e Ciências Exatas (IGCE), Universidade Estadual Paulista (UNESP), 2015. 102 p.

OBSERVATÓRIO CIDADÃO. Mobilidade Urbana: Percepção dos usuários do serviço de transporte coletivo de Piracicaba. Observatório Cidadão de Piracicaba, Boletim № 18, Novembro 2018. Disponível em: http://www.imaflora.org/downloads/biblioteca/5beabcff4dcd8 Boletim18MobilidadeUrbana-TransporteColetivo.pdf. Acesso em: 16 de jul. 2019.

RAMOS, S. Violência, violências: mais agredidas ou mais atentas? In: LIMA, R. S. (org.) Visível e Invisível: A Vitimização de Mulheres no Brasil. 2017. Fórum Brasileiro de Segurança Pública e Instituto DataFolha. Disponível em: http://www.forumseguranca.org.br/wp-content/uploads/2017/03/relatorio-pesquisavs4.pdf. Acesso em: 20 fev. 2019.

RIO CLARO. Diretoria de Comunicação. Prefeitura lança Patrulha Maria da Penha para combater a violência contra a mulher. Rio Claro, 2018. Disponível em: http://imprensa.rioclaro.sp.gov.br/?p=49813. Acesso em: 29 mar. 2019.

SAKRAPLATSER. What is Safeplaces Network? 2018. Disponível em: https://www.sakraplatser.abe.kth.se/en/ Acesso em: 29 ago. 2018.

SÃO PAULO (Estado). Secretaria de Segurança Pública. Dados Estatísticos do Estado de São Paulo. São Paulo, 2018. Disponível em: http://www.ssp.sp.gov.br/Estatistica/Pesquisa.aspx. Acesso em: 29 set. 2018.

SILVA, R. V., et al. Resultado de pesquisa expõe tolerância social à violência contra as mulheres em espaços públicos. In: LIMA, R. S. (org.) Visível e Invisível: A Vitimização de Mulheres no Brasil. 2017. Fórum Brasileira de Segurança Pública e Instituto Data Folha. Disponível em: http://www.forumseguranca.org.br/wpcontent/uploads/2017/03/relatorio-pesquisa-vs4.pdf. Acesso em: 20 fev. 2019.

Estudos Geográficos, Rio Claro, 17(1): 175-195, jan./jun. 2019 (ISSN 1678-698X) http://www.periodicos.rc.biblioteca.unesp.br/index.php/estgeo 
SOUZA, J. R.; SOUZA, M. T. R.; BRAGA, R. Os problemas da mobilidade urbana na periferia Brasileira: O caso do município de Rio Claro, SP. Revista da Casa da Geografia de Sobral, v. 11, p. 61-69, 2009.

VANIER, C.; D'ARBOIS, J.H. Feeling unsafe in public transportation: A profile analysis of female users in the Parisian region. Crime Prevention and Community Safety, 19(3), p. 251-263, 2017. doi:10.1057/s41300-017-0030-7. 